\title{
Os tipos de (estátua) retrato de Augusto ${ }^{1}$
}

\section{The Augustus' (Statue) Portraits Types}

Mayara Amaral Fernandes ${ }^{2}$ 


\section{Resumo}

O presente trabalho aborda o retrato na época de Augusto, o mais importante dentre todos os imperadores romanos, além de ter tido o maior tempo de governo. Ao assumir o poder, Augusto teve a chance de começar algo novo, adotando uma linguagem pictórica conscientemente pensada para assegurar o seu governo e como um modo para mudar as ideias preconcebidas da população. Isto posto, toda a produção de arte era um testemunho do poder e da autoridade do imperador.

Os tipos de retrato são abordados com base na obra de Dietrich Boschung (1993). Para tal, parte-se da relevância que este tipo de representação tridimensional possuía dentro da sociedade romana, tanto para a classe senatorial quanto para a plebe, chegando à representação imperial de Augusto. Diante das inúmeras abordagens praticadas atualmente nos estudos referentes à História da Arte Romana Antiga, optou-se por aquela denominada "arte e contexto", que coloca seu foco na produção, funcionamento e recepção das obras artísticas. Para tal, são utilizados autores como Peter Stewart (2008) que aborda como os objetos artísticos eram produzidos, de que modo funcionavam e de que maneira eram recebidos, tendo como preocupação central o estudo de uma História Social da Arte Romana; e Paul Zanker (1988 e 2012), que considera que as artes visuais são, sobretudo, uma maneira de diálogo delineada pelos valores e realidades da sociedade. Contudo, as questões formais e estéticas não se tornaram

\section{Abstract}

This work approches the portrait at Augustan Era, the most important between all roman emperors, in addition to having more time at the government. When assumed the control, Augustus had chance to start something new, taking a pictorial language consciously designed to ensure your government and as a way to change the preconceived ideas of the population. That said, the entire production of art was a testament to the power and authority of the emperor.

The portraits type are approached based on Dietrich Boschung's (1993) work. For this, this work starts from the relevance of this three-dimensional kind of representation had within the Roman society, both for the senatorial class and for the plebs, reaching the imperial representation of Augustus. Facing the numerous approaches currently practiced in studies on the History of Ancient Roman Art, we opted for that called "art and context," which puts its focus on production, operation and reception of artistic works. To this end, authors like Peter Stewart (2008) are used to discuss how the art objects were produced, how worked and how they were received, with the main concern on the study of a Social History of Roman Art; and Paul Zanker (1988 and 2012), which considers that the visual arts are mainly a way to dialogue outlined the values and realities of society. However, the formal and aesthetic issues have not become obsolete, the fact is that the answers to them are focusing on the historical context and adapted forms for images' messages (Zanker, 2012). Thus, 
obsoletas, o fato é que as respostas para elas estão com o foco no contexto histórico e nas formas adaptadas pelas mensagens das imagens (Zanker, 2012). Desta maneira, a arte passa a ser considerada como um meio de comunicação social e não mais como algo independente.

Palavras-chave: Retrato; Augusto; Arte Romana; Arte e Contexto. the art is now considered as an element of the communication and not as something independent.

Keywords: Portrait; Augustus; Roman Art; Art and Context.

ISSN: 2175-2346

${ }^{1}$ A presente pesquisa foi financiada pela CAPES de outubro de 2014 até maio de 2015; posteriormente o financiamento passou a ser pela no âmbito do convênio CAPES/FAPESP para a concessão de bolsas em instituições públicas e privadas sem fins lucrativos de ensino superior do Estado de São Paulo (processo $n^{0}$ : 2014/24244-9).

${ }^{2}$ Bacharela e Mestra em História da Arte pela EFLCH/UNIFESP, sob orientação do Prof. Dr. José Geraldo Costa Grillo. m.afernandes@hotmail.com 
Retratos são trabalhos artísticos que se comprometem com ideias de identidade e são percebidos, representados e entendidos em diferentes períodos e lugares. A identidade pode conter o caráter, personalidade, posição social, profissão, idade e o assunto do retrato. Tais qualidades não são fixas, mas expressam expectativas e circunstâncias do contexto no qual a obra foi produzida. Tais aspectos não podem ser reproduzidos, mas podem ser sugeridos ou evocados. Este gênero de representação, no entanto, é resultado da predominância de estilos artísticos e técnicas (West, 2004, p. 11). Obras deste tipo merecem um estudo separado, visto que são distintas de outras categorias de arte no modo como são produzidas, na natureza de suas representações e nas suas funções enquanto objetos.

Os romanos, como os gregos, produziam retratos em ocasião de dois contextos principais: a morte e a superioridade em vida (Smith, 1985, p. 209). A criação deste gênero de representação se deu em ambiente patrício, fruto da mentalidade e costumes desta classe. Esta maneira de representação surgiu de uma antiga prática Republicana de produzir máscaras póstumas de cidadãos ilustres ou retratos ficcionais de ancestrais (Figura 1) para exibir em ocasiões públicas ou para expor em locais sagrados juntamente com os tesouros familiares e deuses das famílias mais abastadas (Brilliant, 1974, p. 166). Se o "quem" é de suma importância para os retratos, a identificação do "que" traz um conjunto de tipos de status e características apreciados pelos romanos. Estes tipos, relacionados aos grupos familiares da sociedade, são, geralmente, equivalentes às classes claramente expressas e eram indicadas por meio de atributos simbólicos como as vestes, métodos de disposição e até por distinções estilísticas. Os retratos romanos são reminiscências dos discursos políticos de introdução de modo que apresentam uma pessoa, portanto estabelecem a identidade do indivíduo retratado e colocam-no em um diferente contexto.

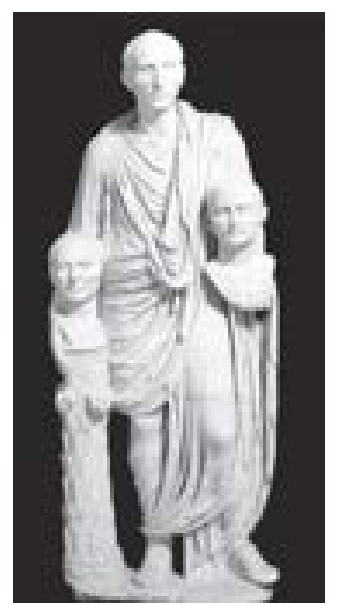

Figura 1. Barberini togado, Museus Capitolinos, Roma (Pollini, 2008, Fig. 13.2A).

A atribuição de uma estátua retrato talvez tenha sido a maior honra pública que uma pessoa podia almejar na sociedade romana. Os interesses centrais neste tipo de representação eram: o desejo de uma honra e glorificação pública, a perpetuação da memória do patrono através da própria imagem do retrato e dos eventos que ocorriam em frente a ele, a reciprocidade entre a cidade e os cidadãos, o interesse pelo modo de representação, o material e a localização da estátua (Fejfer, 2008, p. 3). A 
honra estabelecia a posição do cidadão dentro da sociedade. Para os romanos, este era o melhor modo de demonstrar poder e status e de perpetuar a própria existência. Isto posto, estas representações significaram valores e ideais que eram universais no tempo e espaço para os cidadãos.

A imagem dos líderes romanos é um tema muito abordado nos estudos referentes a Roma. O imperador tinha que ser acessível e visível, além de viver sua vida pública e privada em Roma. Se não fosse possível equilibrar um estilo de vida respeitável e pomposo certamente o seu destino era falhar como líder. O novo tipo de governo precisava de uma linguagem simbólica e visual, a qual seria disseminada e entendida através do Império (Fejfer, 2008, p. 373). Ao passo que o interesse no principado Romano cresceu, o vasto número de retratos e monumentos honoríficos dos imperadores têm sido frequentemente utilizado para ilustrar e tentar reconstruir a política imperial. Tal tipo de representação dos governantes era o meio mais eficaz através do qual se podia atingir este objetivo. Isto vai desde as moedas com as imagens em perfil, passando por itens privados, como as gemas, até os retratos em mármore. A hipótese de que a evidência visual possa refletir ou até constituir uma ferramenta de propaganda imperial se mostrou tão conveniente que é amplamente aceita. Mesmo que estas construções tenham sido oficialmente encomendadas pelo senado e outras entidades políticas, o imperador tinha que aceitá-las como uma honra pessoal, e, além disso, obviamente, aprovar como elas enalteciam e celebravam os seus objetivos. Ademais, o governante podia monitorar e manipular cuidadosamente o modo como ele era honrado. Não há dúvida de que a produção artística escultural comissionada pelo Estado marcou o início de novas modas e gostos que foram imediatamente, ou gradualmente, adotados nas esculturas privadas (Bonanno, 1988, p. 157).

Retratos imperiais, por definição, refletem a retórica e o programa político do governante, que deve apresentar-se como um guerreiro, filósofo, semideus ou modesto mortal, dependendo das circunstâncias (Wood, 2015, p. 267). Roma criou um grupo político no qual os membros dependiam, direta ou indiretamente, da aprovação pública os quais eram, por consequência, preocupados em construir imagens públicas individualizadas. Deste modo, os monumentos honoríficos aos imperadores eram uma reação em direção a auto representação e não uma ferramenta para tal. Os líderes eram enaltecidos e representados por diferentes classes e diversos modos, não apenas porque eram percebidos diferentemente por grupos individuais, mas também porque eles moldavam suas mensagens para atender a audiências específicas (Mayer, 2010, p. 112).

O poder em Roma, e por todo o seu território, estava centrado na figura do Imperador, concentrando nele as responsabilidades econômicas, militares, políticas e religiosas (Martins, 2011). A ligação próxima entre o governante e o seu retrato, bem como o fato de que estes retratos eram copiados ao longo do império, sem dúvida os tornam fontes indispensáveis para o entendimento da representação dos líderes romanos na capital, de onde vem grande parte das evidências e onde os protótipos eram criados. Por outro lado, os retratos imperiais das províncias frequentemente mostram um imperador muito diferente dos protótipos romanos que os inspiraram. 
Otávio, que era sobrinho neto e filho adotivo do Julio César ${ }^{1}$, foi o primeiro Príncipe $^{2}$ de Roma, além do mais importante dentre todos os imperadores romanos, que por mais tempo governou. Ele reúne em si as funções de César, Imperador ${ }^{3}$, Príncipe e Pontífice ${ }^{4}$. Entretanto, para Paulo Martins (2011), em um momento de muita instabilidade política devido a incessante guerra civil, a sua tarefa para adquirir a confiança de seus súditos era muito delicada.

Quando começa sua ascensão ao poder, ele tinha apenas 19 anos, aos 32 comandava todo o território romano. Portanto, era necessária uma nova imagem para expressar uma nova era (Kleiner, 1992, p. 61). Deste modo, Otávio se colocou como o grande exemplo de cidadão tanto em sua vida privada quanto nas aparições públicas. O seu estilo público possuía simplicidade e dignidade, desde o seu modo de andar até a maneira de discursar, indo da sua relação amigável com as pessoas humildes aos senadores. A sua modéstia e simplicidade são mais evidenciadas através das honrarias que ele continuamente recebeu. Todos os monumentos construídos em sua homenagem tinham caráter votivo e religioso (Zanker, 1988, p. 160). Ele rejeitou o estilo de retrato honorífico republicano e optou por um retrato mais simples que o mostrasse velado e togado, visto que a toga era o reconhecimento da tradição, a promessa de respeitar a República. Conscientemente, os artistas da época se concentravam em temas como a vitória, paz e piedade. Sob seu governo, o retrato está intrinsecamente "ligado à expressão artística oficial, de defesa e de propaganda" (Argan, 2003, p. 206). Os retratos de Otávio ocupam uma posição importante dentro da imagem imperial romana, devido a sua auto representação e reprodução, visto que foi o primeiro governante a ter a sua imagem amplamente disseminada, além de ter sido o mais retratado entre todos os líderes (Smith, 1996, p. 31).

O Príncipe e sua família foram imortalizados em retratos individuais e em grupo, ambos em tamanho real ou em versões em miniatura, bem como em moedas e camafeus preciosos. Em suas representações a sua imagem é sempre sem sinais de envelhecimento, mesmo as que datam do final de sua vida. Além disso, possui características consistentemente reconhecíveis, mas também há mudanças estilísticas demarcadas. Os seus primeiros retratos, do período da guerra civil, são marcadamente dramáticos, com cabelo espesso, expressão intensa e um forte pescoço (Wood, 2015, p. 264). Depois que Otávio se torna imperador e adquire o título de Augusto, em 27 a. C., a sua aparência adquire expressões serenas e poses mais silenciosas, adequadas ao fundador da Paz Augusta. As estátuas com características heroicas dão vez a apresentação do Primeiro cidadão romano em suas capacidades estritamente constitucionais, vestindo toga ou uniforme militar (Hallet, 2005, p. 160-169). Ao consolidar seu poder, o Príncipe precisava convencer o senado de que ele não ambicionava a monarquia e que pretendia exercer apenas a autoridade que foi concedida a ele.

Durante o seu governo possuiu alguns tipos de retrato, os quais atendiam as necessidades e exigências da representação de conjetura do momento. Ele constrói sua

\footnotetext{
1 Júlio César foi um líder militar e político que fez parte do Primeiro Triumvirato (aliança política que dividia o território romano entre três cônsules, os quais eram responsáveis pelo governo de cada parte concedida) com Pompeu e Crasso e que, posteriormente, se tornou ditador perpétuo de Roma vindo a ser assassinado por ocasião de uma conspiração senatorial. A sua atuação política e militar foi de suma importância durante a transição da época republicana de Roma para a imperial.

2 Do latim Princeps, primeiro homem (Cf. Kousser, 2015, p. 120).

3 Do latim Imperator, a mais alta patente do exército romano.

4 Do latim Pontifex Maximus, chefe da religião romana.
} 
imagem pública por meio de suas atividades civis, militares, políticas e religiosas, as quais irão originar um tipo específico de representação, que, ao final de seu governo, transformar-se-ão em um grande número de representações que serão sintetizadas com a divinização (Martins, 2011, p. 179).

Visto que o número de exemplares de retratos dessa época é vasto, é difícil considerar cada obra como única. Deste modo, é possível separá-las em grupos menos amplos que são norteados por um original comum, dos quais surgem os tipos ou modelos iconográficos (Schollmeyer, 2007, p. 41). Uma das características mais relevantes para essa classificação é a disposição do cabelo, em particular na parte frontal da cabeça. Conforme a classificação e nomeação de Dietrich Boschung (1993), existem cinco tipos de retrato de Augusto, a saber: "Alcudia" (Otaviano ou Ácio), "Lucus Feroniae", "Bèziers-Spoleto", "Paris Louvre" (Forbes) e Prima Porta, segundo a nomeação do próprio autor. Para John Pollini (1999), Boschung categoriza os retratos de Augusto, principalmente, a partir dos penteados e, em menor grau, através das características faciais. Para ele, o autor pretende determinar a aparência do modelo para um tipo particular. Isto posto, os retratos mais refinados refletem o estilo da capital do império e possuem grande correspondência entre si, o que enfatiza a hipótese de serem réplicas de um modelo em comum. O autor estabelece o que ele chama de "Kerngruppe", ou grupo principal, dentro de cada tipo de representação, que serviam de modelo para a concepção das réplicas e cópias que circulavam pelo território romano. Todavia, outros autores como: Patrick Schollmeyer (2007) e Tonio Hölscher (2010) estabelecem três tipos de retrato de Augusto, visto que dentre os tipos postulados por Dietrich Boschung (1993), dois deles são quase subtipos, ou tipos menores, contando com menos de cinco réplicas cada. Por este motivo, são abordados neste trabalho três tipos principais: Otaviano, Forbes e Prima Porta.

\section{Tipo Otaviano ou Ácio}

O primeiro tipo de retrato é chamado de Otaviano (ou Ácio, em ocasião da batalha contra Marco Antônio), o qual Boschung denomina de "Alcudia", depois de uma cabeça encontrada em Alcudia. Neste caso, são quatro obras as representantes do grupo principal, seguidas de mais 24 esculturas que também refletem este estilo, em menor grau. Aqui, a análise deste autor traz à tona um dos problemas intrínsecos nos estudos tipológicos, que fazem comparação entre as cabeças existentes como um meio de reconstrução do protótipo perdido, isto é, a evidência auto limitadora dos retratos, a qualidade e o ângulo disponível das vistas fotográficas de cada cabeça.

É possível afirmar que o tipo Otaviano estabeleceu o primeiro modelo de retrato tridimensional de Otávio, sendo que a criação deste tipo de retrato é datada, provavelmente, de 40 a. C (Hölscher, 2010, p. 261). Nestas representações existe um senso de realismo fisionômico o qual é acentuado de maneira artística proveniente do "Pathosbild" Helenístico, que representa a grande carga emocional da imagem (Pollini, 1999). Desta forma de representar vem a torção acentuada e a inclinação da cabeça, com as mechas de cabelo que aparentam estar um pouco mais movimentadas sobre a testa e as sobrancelhas mais tensas. $O$ cabelo é suavemente disposto e com a presença de três mechas no centro da testa formando uma "pinça" à direita e 
um "garfo" à esquerda e as características faciais são joviais. O conjunto harmônico destas formas, cuja produção é impensável independentemente umas das outras, define o tipo Otaviano (Höslcher, 2010, p. 261). O dinamismo deste tipo é por vezes enfatizado pela torção para o lado direito. Contudo, para John Pollini (1999), esta imagem do governante está distante do "Pathosbilder" romano republicano. Para ele, o pathos foi enfatizado neste tipo, especialmente no que diz respeito ao tratamento da pele e do cabelo mais elaborado nas laterais. Há bastante movimento e, talvez, emoção nos retratos deste tipo, o que leva até as imagens reais da Grécia Helênica (Walker, 1995, p. 66).

O período em que se inserem as produções deste tipo é o segundo triunvirato, constituído por Otávio, Marco Antônio, um dos homens de confiança de Júlio César, sobretudo no exército, e Lépido, com o intuito de organizar politicamente o território romano. Tal aliança durou oito anos, até a saída de Lépido e depois o crescente desentendimento entre os outros dois membros, que culminou na famosa Batalha do Ácio, referida anteriormente. Esta representação foi recorrente durante este período, tendo sido amplamente difundida, mostrando Otávio no início de sua carreira política como um líder triunfante e enérgico (Hölscher, 2010, p. 261). Ele era representado como a resposta contra a ameaça estrangeira de Cleópatra, rainha do Egito com a qual Marco Antônio havia fugido. Deste modo, Otávio aparecia como o sucessor dos reis que tinham governado a parte oriental do Mediterrâneo desde a morte de Alexandre, o Grande (Walker, 1995, p. 65).

É importante rememorar que para a tradição Ocidental, era Alexandre quem incorporava o que significava ser tanto um líder do exército, quanto o criador de um império (Pollini, 2012, p. 162). Além disso, ao se comparar a ele, Otávio conseguiu transformar sua juventude e falta de experiência militar em uma vantagem política, pois Alexandre tinha apenas vinte anos quando se tronou sucessor de seu pai, Felipe da Macedônia. $O$ argumento central deste modo de representar é a necessidade de propagação da ideia de unidade da República que persuadisse a população, de modo a honrar Otávio como "triúnviro e restaurador da República" (Pollini, 2012, p. 167). Visto que era preciso haver uma representação mais próxima da realidade, optou-se pela aproximação da figuração republicana, retratando de acordo com as características reais do indivíduo (Martins, 2011, p. 180). Além disso, essa imagem precisava compensar a juventude e inexperiência de Otávio, de modo a refletir sua autoridade.

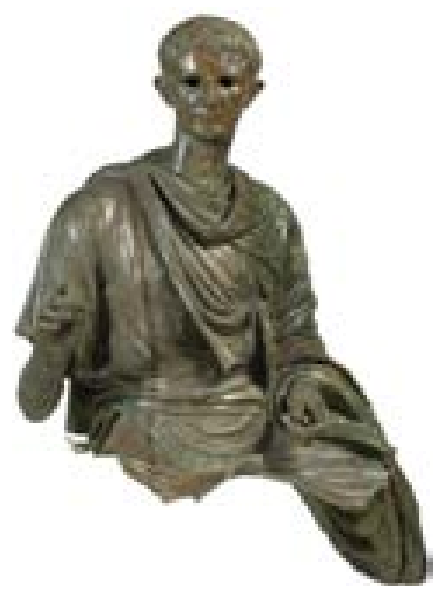

Figura 2. Augusto Equestre, Museu Arqueológico Nacional, Atenas (fotografia oficial da instituição). Fonte: http://www.namuseum.gr/collections/sculpture/roman/roman02-en.html, acessado em 27/03/2016. 


\section{Tipo Forbes}

Após a Batalha do Ácio e o subsequente fim do segundo triunvirato, Otávio passa a ser associado metaforicamente a Apolo, de modo a aumentar e associar o seu poder de triúnviro para o de Júlio César, antes de seu assassinato. Deste modo, a sua representação adquire caráter divino, visto que sua imagem como Apolo foi profundamente disseminada. Tal recorrência de associação a esse deus, somada à relação a Alexandre Magno, constitui a sua marca cultural que, além das campanhas militares, implementou uma nova política cultural norteada pelo mecenato (Martins, 2011, p. 182-184). O tipo Forbes é mais evidentemente influenciado pelo classicismo grego do que os retratos anteriores, talvez pelo fato dele almejar ser representado como o portador da estabilidade após o período da guerra civil. Em 27 a. C. Otávio recebe o título de Augusto oferecido pelo Senado. Neste momento, ele precisava se apresentar como não menos do que o primeiro cidadão da República restaurada. Em decorrência disto, os primeiros retratos derivados das tradições reais da retratística do leste grego não seriam mais adequados para retratá-lo.

Este modo de representar teria servido não só para comemorar o seu triunfo em 29 a. C., mas também para celebrar a paz que ele tinha finalmente trazido para o mundo romano. Para comemorar a fundação da nova forma de governo, o Principado, bem como a assunção de seu novo nome, uma nova imagem era necessária e era preciso que ela fosse retrospectiva e prospectiva: retrospectiva na medida em que convidava à comparação com o protótipo ideal do passado grego clássico e prospectiva, no sentido que refletia o otimismo do Principado de Augusto e o transformava no novo modelo do ideal heroico. A característica principal deste tipo são as mechas dispostas muito próximas umas das outras, desde a extremidade frontal esquerda até a direita, que se inclinam suavemente para baixo. Além disso, a face tem traços mais finos e feição mais suave (Hölscher, 2010, p. 261).

A datação do protótipo deste tipo é bastante debatida. Alguns pesquisadores estabelecem uma data anterior ao tipo Prima Porta. Duas hipóteses são aceitas: a vitória contra os Partos, em 20 a. C., ou a celebração da nova época áurea, que teve início em 17 a. C. Os traços sutis e distintos deste tipo de retrato estão alinhados com a ideologia da paz trazida por Augusto.

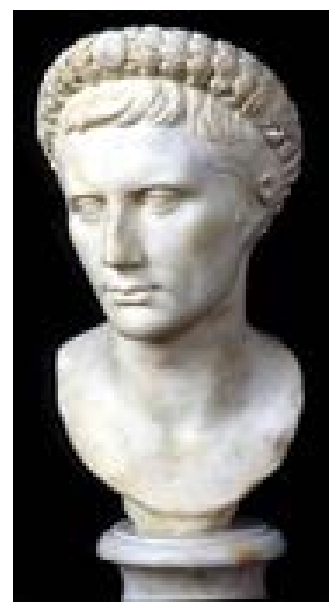

Figura 3. Augusto com coroa cívica, Museus Capitolinos, Roma (fotografia oficial da instituição).

Fonte: http://www.museicapitolini.org/collezioni/percorsi_per temi/ritratti imperiali/ritratto di_augusto, acesso em 27/04/2016. 


\section{Tipo Prima Porta}

Este modo de representar é fortemente classicizante e teria sido criado logo após a fundação do principado, em 27 a. C. Este é o último tipo de representação do Príncipe, levando este nome em decorrência da icônica estátua de Augusto de Prima, encontrada na Villa de Lívia, esposa de Augusto, em Prima Porta no ano de 1863. John Pollini (2012) também sugere o nome de Tipo Príncipe. Dietrich Boschung (1993) catalogou 148 réplicas pertencentes a este grupo, além de mais seis camafeus. As características mais influenciadoras neste gênero representativo são o formato de sua cabeça, suas sobrancelhas e o seu corte de cabelo, sobretudo este último (Pollini, 1999; Squire, 2013).

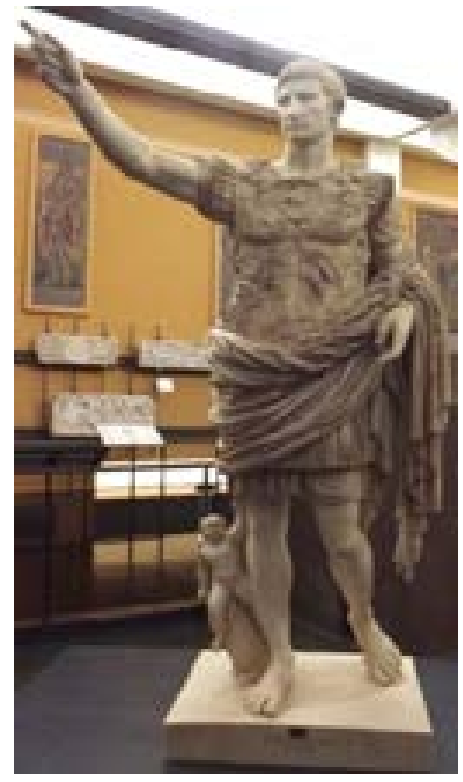

Figura 4. Augusto de Prima Porta, Museus do Vaticano, Roma (Fotografia da autora).

Há muito tempo, vários pesquisadores defendem a ideia de que o projeto desta obra remete a protótipos gregos, de meados do século $V$ a. $C$., mais especificamente ao Doríforo, de Policleto, o qual representava o corpo ideal, no cânone grego, e que foi muito usado como modelo a ser seguido e copiado em Roma. Entretanto, conforme afirma Anthony Bonanno, neste exemplar ele foi "suprimido em conformidade com os conceitos tradicionais romanos de dignidade e sobriedade" (Bonanno, 1994, p. 85). Neste tipo as características faciais são ainda mais clássicas, calmas e idealizadas do que nos outros, convidando a comparar com os protótipos gregos mais do que com a influência emocional da retratística de Alexandre e seus sucessores helenísticos. Desta maneira, a prospectiva esperada era otimista e esperava que o principado de Augusto e ele próprio fossem os modelos a serem seguidos e emulados pelos futuros líderes romanos e não mais Alexandre, o Grande (Pollini, 2012, p. 175). 


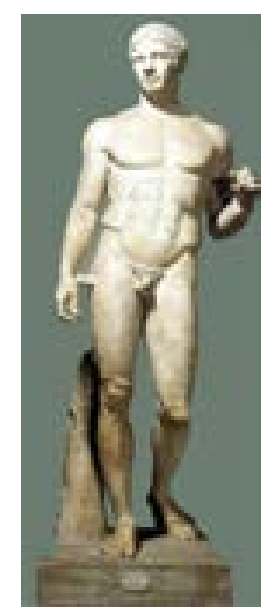

Figura 5. Doríforo, Museu Arqueológico Nacional, Nápoles (fotografia oficial da instituição). Fonte: http://cir.campania.beniculturali.it/museoarcheologiconazionale/itinerari-tematici/nel-museo/collezioni-pompeiane/RIT RA71/?searchterm=policleto, acesso em 27/04/2016

Paul Zanker afirma que este retrato "não hesita em celebrar o conquistador radiante e faz clara referência à sua ancestralidade divina" (Cf. Zanker, 1988, p. 189). Para ele, a couraça transmite uma nova concepção de vitória. A cena retratada nela é sobre o retorno a Roma do estandarte roubado pelos Partos, em 20 a. C. (Burnett, 1981; Walker, 1981); no centro estão duas figuras masculinas: à esquerda um representante das legiões romanas ou, talvez, Marte Ultor, Tibério, Rômulo ou Enéias, com um animal no meio de suas pernas, que pode ser um cachorro ou uma loba; à sua frente está um homem, possivelmente um líder dos Partos, com vestes tipicamente orientais e barba, segurando, com as duas mãos, o estandarte militar encimado por uma águia. O personagem romano está com o braço direito estendido, provavelmente para receber o estandarte ou como um gesto de paz (Squire, 2013). Este episódio ainda era muito recente na memória do povo de Roma e Augusto teve grande contribuição nele e na sua significação política, tanto que ele descreve o ocorrido em seu testamento. Além disso, este acontecimento foi um importante elemento para a mitologia do Imperador, tido como um acontecimento cósmico onde os deuses são representados para atestar a supremacia dele.

Ainda na parte central, agora nas suas extremidades, estão duas personagens femininas: à esquerda, uma mulher vestida com uma túnica de maga longa, um manto, sandálias abertas, cabelos presos para trás e uma espada na mão, possivelmente representando a província romana da Hispania; à direita, a outra figura aparece com uma faixa no cabelo, com a bainha de uma espada vazia em uma mão e, na outra, um instrumento musical, neste caso a associação é com a Gália. Abaixo se encontram dois deuses: na parte esquerda Apolo com sua lira e na direita, sua irmã Diana, os dois patronos de Augusto. Na parte mais baixa da couraça está representada mais uma mulher, com dois bebês, que pode ser considerada como Telure, Itália ou Cibele. No topo, em ambos os lados, estão duas esfinges com as cabeças voltadas para o espectador e os corpos para a parte interna. Na parte peitoral da representação, da direita para a esquerda, estão: o Sol em uma quadriga; o deus Céu com seu manto ondulado; a Lua segurando uma tocha com a mão esquerda e a Aurora (Squire, 2013).

Esta escultura não tem como objetivo forjar a imagem particular do Imperador, 
ela faz parte do sistema de comunicação visual implantado por ele. A estátua trás o significado do regime político assumido por Augusto. A partir da vitória sobre os Partos, para Zanker (1988), é celebrado o surgimento de uma perfeita ordem mundial, com a benção dos deuses. Deste modo, este acontecimento é tido como a condição e consequência da Era de Augusto, o qual se torna a representação da divina providência e da vontade dos deuses, através da virtude herdada deles, de modo a trazer a harmonia entre o Estado e o divino.

Indubitavelmente, este é o tipo de retrato mais popular da época de Augusto, visto que o seu número de réplicas e versões ultrapassa o dobro dos outros tipos existentes. As esculturas retrato são surpreendentemente dominadas por ele e é notável o grande impacto classicizante nestas representações. Tal fato se deve à simplicidade de seu penteado e ao arranjo das mechas de cabelo sobre a testa. Neste modo de representação apenas uma mecha de cabelo é disposta no meio da testa, a qual juntamente com as mechas adjacentes forma uma "pinça" e um "garfo". A face é mais ampla e menos serena, enquanto a testa e as bochechas formam uma convexidade mais pronunciada; as sobrancelhas e a boca aparecem com mais ênfase. A ampla e simples convexidade da face, o tratamento diverso dado as mechas de cabelo, arqueadas e sobrepostas, criam uma composição clara caracterizada pelo movimento do contraposto. Sua cabeça não aparece mais virada para um lado, mas sim para frente e mais significativa e tranquilizadora do que tensa e enérgica. $O$ corpo pequeno e com cicatrizes passa a ter proporções heroicas e perfeitas (Walker, 1995, p. 66). Por todos estes motivos, este é o tipo de retrato criado para o programa do "classicismo" de Augusto (Hölscher, 2010, p. 261).

Além disso, é notável a falta de sinais de idade avançada nas representações, como ocorria nos retratos republicanos. Augusto e Lívia nunca tiveram suas idades reveladas em seus retratos, mesmo no final de suas vidas; isto se deve ao fato de que as suas representações não eram intencionadas a serem semelhantes a realidade. Elas eram cuidadosamente construídas não a partir do indivíduo, mas do filho divino Augusto, o grande líder que possuía os traços eternamente joviais (Kleiner, 2010, p. 67).

Para John Pollini (1999), este tipo de representação de Augusto contém o novo ideal heroico, entre conceitos clássico e clássico tardio. Deste modo, é criado o novo ideal heroico do Príncipe. A imagem deste novo retrato de Augusto conseguiu capturar o imaginário popular, como é possível notar pelo grande número de réplicas existentes por todo o império. Assim como os tipos anteriores, a imagem oficial foi reinterpretada em diferentes graus, com uma vasta gama de tratamentos estilísticos para as características faciais. Esta nova concepção de representação do imperador continuou a ser usada também por seus sucessores por quase um século.

\section{Considerações finais}

Augusto aparece como uma solenidade suspensa aos cânones do tempo, de tal modo que este tipo iconográfico foi usado e imutável até sua morte. As formas clássicas, inspiradas em Policleto, mostram o ideal romano de dignidade nas aparições públicas do imperador, além de atribuir sentido na expressão programática do título 
Augusto. Tais fatores elucidam a razão da maior parte dos retratos desta época serem do tipo Prima Porta de retrato.

Augusto foi deificado após sua morte e desempenhou um papel importante na política dinástica dos governantes subsequentes e, por isso, a sua imagem continuou a ser reproduzida durante os principados de seus sucessores. Tal fato contribui para a problemática da datação, sendo que muitas vezes é extremamente delicado estabelecer, até mesmo, a data de uma obra, em termos estilísticos, devido ao ecletismo e às várias práticas artísticas. Os retratos dos príncipes da família imperial foram empregados para familiarizar as pessoas, especialmente o exército, com os vários candidatos a sucessão, como por exemplo, Caio e Lúcio, netos de Augusto que foram adotados como sucessores, mas que deram lugar a Tibério, filho de Lívia, devido a suas mortes precoces.

A influência da retratística de Augusto demasiadamente expressiva a ponto de, no período que compreende a primeira dinastia imperial romana, ter sido estabelecido o bem sucedido tipo Júlio-Claudiano de representação. Os retratados deste gênero não possuíam barba, eram graves e sérios, com os cabelos modestamente arranjados e sempre se vestiam de maneira específica. Este tipo foi emulado também no âmbito privado, tamanho era o desejo das demais classes em se parecer com membros da família imperial (Bonanno, 1998, p. 159). Além disso, com a divinização de Augusto, após a sua morte, os seus retratos continuaram a ser venerados, juntamente com os de Júlio César e com os de outros imperadores posteriores a ele, de modo a formar uma espécie de panteão do Império. Em grupo, ou individualmente, eles recebiam adornos complementares e, até mesmo, sacerdócios especiais ligados ao culto imperial (Frel, 1981, p. 5).

\section{Referências}

ARGAN, Giulio C. História da arte italiana - 1. Da Antiguidade a Duccio. São Paulo: Cosac Naify, 2003.

BONANNO, Anthony. Sculpture. In: HENIG, Martin (ed.). A Handbook of Roman Art A survey of the Visual Arts of the Roman World. London: Phaidon Press, 1994.

Imperial and Private Portraiture: a case of non-dependence. In: BONACASA, Nicola e RIZZA, Giovanni (org.). Ritratto ufficiale e Ritratto Privato Atti dela II Conferenza Internazionale sul Ritratto Romano. Roma: Consiglio Nazionale dele Ricerche, 1998, p. 157.

BOSCHUNG, Dietrich. Die Bildnisse des Augustus. Berlim: Gebr. Mann Verlag, 1993.

BRILLIANT. Richard. Roman Art - from the Republic to Constantine. London: Phaidon, 1974.

BURNETT, Andrew. The Image of Augustus. London: British Museum Publications, 1981. 
FEJFER, Jane. Roman Portraits in Context. Berlin: Walter de Gruyter, 2008.

FREL, Jiři K. Roman Portraits in the Getty Museum. Tulsa: Philbrook Art Center, 1981.

HALLETT, Christopher H. The Roman Nude: Heroic Portrait Statuary 200 BC-AD 300. Oxford: Oxford University Press, 2005.

HÖLSCHER, Tonio. L'Archeologia Classica: Un'Introduzione. Roma: L'Erma di Bretschneider, 2010.

KLEINER, Diana E. E. Roman Sculpture. Yale: Yale University Press, 1992.

KLEINER, Fred S. A History of Roman Art. Boston: Wadsworth Cengage Learning, 2010.

KOUSSER, Rachel. Adapting Greek Art. In: BORG, Barbara E. (ed.). A Companion to Roman Art. Oxford: Wiley Blackwell, 2015.

MARTINS, Paulo. Imagem e Poder. Considerações sobre a representação de Otávio Augusto. São Paulo: Edusp, 2011.

MAYER, Emanuel. Propaganda, staged appaluse, or local politics? - Public Monuments from Augustus to Septimus Severus. IN: EWALD, Björn C. e NOREÑA, Carlos F. (ed.). The Emperor and Rome - Space, Representation, and Ritual. Nova York: Cambridge University Press, p. 111-134, 2010.

POLLINI, John. Die Bildnisse des Augustus by Dietrich Boschung. The Art Bulletin, Vol. 81, No. 4, p. 723-735, 1999.

. Ritualizing death in Republican Rome: memory, religion, class struggle, and the wax ancestral mask tradition's origin and influence on veristic portraiture. In: LANERI, Nicola (ed.). Performing Death - Social analyses of funerary traditions in the ancient near east and mediterranean. Chicago: The Oriental Institute, 2008.

From the republic to empire: rhetoric, religion, and power in the visual culture of ancient Rome. Norman: University of Oklahoma Press, 2012.

SCHOLLMEYER, Patrick. La scultura romana: Un'introduzione. Roma: Apeiron, 2007.

SMITH, Roland R. R. Typology and diversity in the portraits of Augustus. Journal of Roman Archeology, Vol. 9, p. 31-47, 1996.

SQUIRE, Michael. Embodied Ambiguities on the Prima Porta Augustus. Art History, Vol. 36, p. 242-279, 2013. 
WALKER, Susan. The Image of Augustus. London: British Museum Publications, 1981. Greek and Roman Portraits. London: British Museum, 1995.

WEST, Shearer. Portraiture. Oxford: Oxford University Press, 2004.

WOOD, Susan. Portraiture. In: FRIEDLAND, Elise A., GAZDA, Elaine K. e SOBOCINSKI, Melanie Grunow (ed.). The Oxford Handbook of Roman Sculpture. Nova York: Oxford University Press, p. 260-275, 2015.

ZANKER, Paul. The Power of Images in the Age of Augustus. Michigan: The University of Michigan Press, 1988.

Arte Romana. Roma: Editori Laterza, 2012. 